\title{
Formation of Perspective Composite Coatings by Ion-Beam Assisted Deposition
}

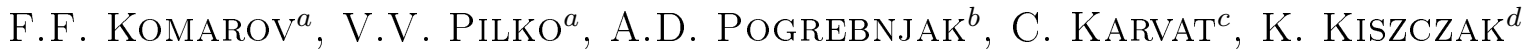 \\ AND C. KOZAK \\ ${ }^{a}$ Institute of the Applied Physics Problems, Kurchatov St., 7, 220108, Minsk, Belarus \\ ${ }^{b}$ Sumy University, R. Korsakov St., 2, 40007, Sumy, Ukraine \\ ${ }^{c}$ Technical University in Lublin, Nadbystrzycka 38D, 20-618 Lublin, Poland \\ ${ }^{d}$ Maria Curie-Skłodowska University, pl. M. Curie-Skłodowskiej 1, 20-031 Lublin, Poland
}

\begin{abstract}
TiAlN, TiSiN, and TiCrN composite layers were deposited by magnetron sputtering and sliding — angle ion beam sputtering of the inner surface of hollow truncated cones of different compositions. The composition of both type coatings and component depth distributions were studied by the Rutherford backscattering spectrometry. The structural and phase analyses of the deposited films were performed by transmission electron microscopy and diffraction. Microhardness, wear resistance and friction coefficient of the coatings were also measured and discussed in the relationship with the structure and composition. Microhardness tests showed that the registered data varied in the range 10 to $50 \mathrm{GPa}$, depending on composition and concentration of components. The best wear protection results from the magnetron deposited $\mathrm{Ti}-\mathrm{Al}-\mathrm{N}$ systems in a narrow range of component concentrations. A minimal friction coefficient was revealed for the magnetron sputtered layers.
\end{abstract}

DOI: $10.12693 /$ APhysPolA.123.800

PACS: $68.55 . \mathrm{Nq}$

\section{Introduction}

Current research is directed towards designing multicomponent materials that accomplish multiple performance objectives in a single system or advanced materials exhibiting improved or outstanding performance. Examples of both possibilities can be found in the field of protective coatings, combining hardness with other suitable properties as low-friction, thermal and wear resistance. In fact, hardness is traditionally the most demanded property for protective coatings. Nanocomposites are structures conceptually similar to polycrystals but including the second phase among crystals. As a result, they are formed by nanosized crystals (typically, based on hard phases as nitrides or carbides) embedded in the second phase. The nature of components, crystal size, and amount of each phase determine the final properties of the composite material [1-3].

Hard coatings, such as TiN deposited on machining tools, have been widely used for increasing lifetime and performance of cutting tools $[4,5]$. However, TiN begins to oxidize in air at $500^{\circ} \mathrm{C}$, which limits its industrial application in high speed and dry machining [6]. The TiAlN and TiSiN nanocomposites consisting of TiN nanocrystals embedded in the amorphous $\mathrm{AlN}$ or $\mathrm{Si}_{3} \mathrm{~N}_{4}$ phases $[3,7]$ have exhibited a super hardness and excellent thermal stability, being widely applied in dry and high-speed cutting treatments [8]. The $\mathrm{TiCrN}$ nanocomposite is also of great interest from the point of view of practical applications [9]. The main task of this paper is to find a correlation between the composition and structure of the coating and its mechanical and tribological properties.

\section{Experimental procedure}

The substrates in all cases were made of polished stainless steel, graphite, silicon and single crystal sodium chloride plates freshly split. Magnetron depositions were performed with the usage of $\mathrm{Ar}^{+}$ions for the $\mathrm{Ti}-\mathrm{Al}-\mathrm{N}$, $\mathrm{Ti}-\mathrm{Si}-\mathrm{N}$ and $\mathrm{Ti}-\mathrm{Cr}-\mathrm{N}$ systems by the sputtering of composite targets containing $\mathrm{Ti}$ as a main component and $\mathrm{Al}$, $\mathrm{Si}$ and $\mathrm{Cr}$ as the addition in the concentrations from 10 up to 50 at.\%. The optical spectra analyzer S-100 was used to control the nitrogen flow. The gradient layers were formed on the stainless steel samples by the alteration of nitrogen flow steering from 0 up to $0.4 \mathrm{~Pa}$. To improve coating properties mentioned in Introduction, a bias voltage of 150-200 $\mathrm{V}$ was used. The vacuum chamber was evacuated to a base pressure of $5 \times 10^{-3} \mathrm{~Pa}$, and prior to deposition the substrates were cleaned by $\mathrm{Ar}^{+}$sputtering at a bias voltage of $1.5 \mathrm{keV}$ for 30 min to remove residual pollutants and native oxides. The infrared light heating of the samples up to $150-240^{\circ} \mathrm{C}$ allows increasing the adhesion between coatings and substrates.

The use of the conical system (see Ref. [10]) makes it possible to carry out in situ material deposition with an assistance of ions scattered on the cone surface. The hollow truncated cones coated with layers of the desired materials $(\mathrm{Ti}-\mathrm{Cr}-\mathrm{Cu}$ or $\mathrm{Ti}-\mathrm{Si}-\mathrm{Cu}$ ) were irradiated by $60 \mathrm{keV}$ $\mathrm{Ar}^{+}$or $\mathrm{Xe}^{+}$ions to a fluence of $2.5 \times 10^{17} \mathrm{ion} / \mathrm{cm}^{2}$ at a beam current density of $10 \mu \mathrm{A} / \mathrm{cm}^{2}$. The chosen energy of ions corresponds to efficient sputtering of materials used in our experiments. A special sample holder has been designed [10] to improve the adhesion of deposited layers and introduce an additional flexibility of processing. It also allows to cool the samples with running water during the irradiation procedure and to clean the sam- 
ple surface by low-energy ion bombardment. In order to analyze the depth distribution of atomic species in the deposited layers, the Rutherford backscattering spectrometry (RBS) was applied. The RBS measurements were performed with $1.3 \mathrm{MeV} \mathrm{He}{ }^{+}$. Structural properties of coatings were studied by means of transmission electron microscopy (TEM) and diffraction (TED). The TEM investigations in plan-view $(\mathrm{PV})$ geometry were carried out using a $200 \mathrm{keV}$-Hitachi H-800.

Microhardness of coatings was measured by means of a DuraScan 20 equipment. To find the hardness and the elastic modules at different loads, we used the OliverPharr technique [11] (Shimadzu Dynamic Ultra Micro Hardness Tester DUH-202). The tribological properties were evaluated by unlubricated disc-on-plate friction tests. Normalized wear rates were evaluated from the cross-sectional profiles taken across the disk wear track after testing by means of stylus profilometry.

\section{Results and discussion}

A short overview of the measured RBS spectra of deposited coatings by magnetron sputtering shows us some critical points for this deposition method. The typical RBS spectra in Fig. 1 illustrate a gas flow control effect. A strong influence of the reactive gas flow intensity is observed in this figure. The RBS measurements of coating composition show that the best compositional uniformity of layers (see a profile of the titanium peaks in Fig. 1) was achieved by the usage of the optically controlled magnetron sputtering.

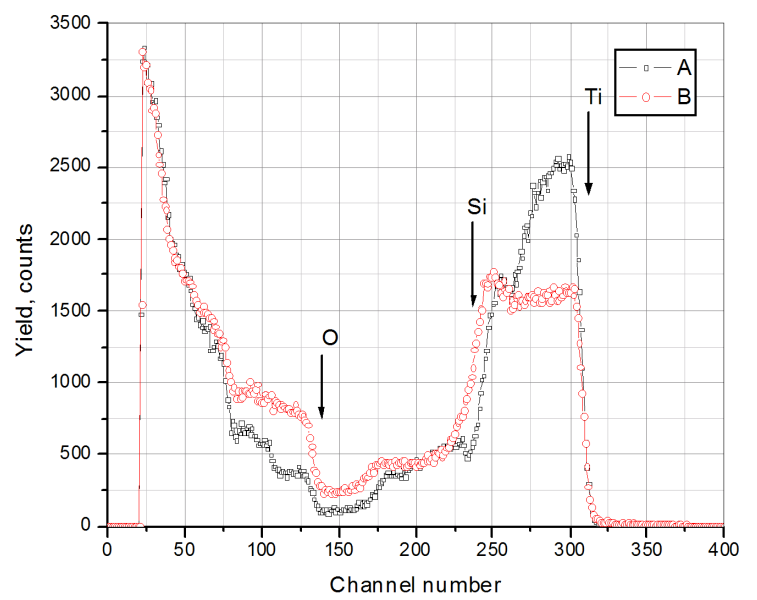

Fig. 1. Typical RBS spectra of the thin Ti-Si-N layers, deposited without the optical control (A) and with the steering (B).

Moreover, the RBS spectra enable us to register high concentration of oxygen (up to 30 at.\%) in the deposited layers (Fig. 1). This contamination may be caused by the oxygen flow from the residual gases and the target surface oxide. The oxygen concentration decreases up to $6-10$ at.\% only by the previous long-time (about $1000 \mathrm{~s}$ ) "training" of the sputtered target (Fig. 2).
The "beginning-stage" of oxygen contamination must be eliminated for all magnetron sputtered targets with the substrate shielding in the initial stage of processing. An example of the RBS spectrum for a thick homogeneous magnetron coating, deposited from the previously cleaned target, is shown in Fig. 2.

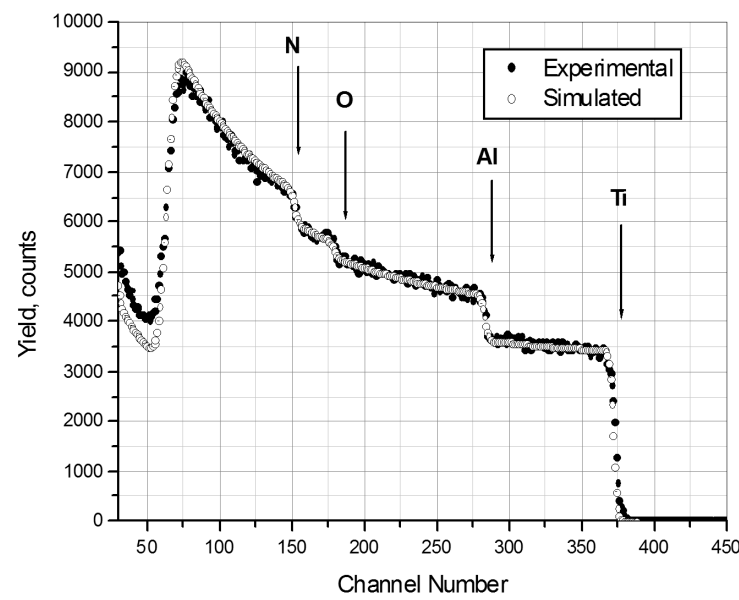

Fig. 2. Typical RBS spectrum of the thick Ti-Al-N layer, deposited with the optical control and the results of the spectrum modeling.

To perform the wide-range energy spectrum modelling, specially developed "Head 6" software was used. The basic advantage of the used simulation procedure over the conventional programs is the account of the ion detection equipment non-linearity by the original calibration procedure and the four-point polynomial fit. As can be seen in Fig. 2, atomic composition of this thick layer was homogeneous, and the oxygen concentration was considerably lower than in the cases presented in Fig. 1. According to calculations done for this spectrum, the $\mathrm{Al} / \mathrm{N}$ ratio was about 0.82 and total concentration of light components (N,O) amounts to about 58 at.\%. That allows us to suppose that a part of the oxide with the largest oxygen concentration $\left(\mathrm{TiO}_{2}\right)$ in the coating is very small. A negative effect of oxygen in the deposited layers on hardness and tribomechanical properties of such coatings was discussed in Ref. [3]. These results illustrate significant importance of target pretreatments as well as the reactive gas flow control.

The hollow truncated cones [10] coated with the foils of $\mathrm{Ti}, \mathrm{Si}$, and $\mathrm{Cu}$ or $\mathrm{Ti}, \mathrm{Cr}$ and $\mathrm{Cu}$ have been irradiated by $60 \mathrm{keV} \mathrm{Ar}{ }^{+}$or $\mathrm{Xe}^{+}$ions to the fluence of $2.5 \times 10^{17} \mathrm{~cm}^{-2}$. Using this method, a number of three-component materials have been deposited on the stainless steel and graphite samples. Atomic composition of deposited layers has been controlled by an area of the segments of materials being sputtered. When the cone surface is covered with segments of various materials, it enables production of multicomponent layers including high-temperature materials and those containing elements immiscible under equilibrium conditions. 
The RBS spectra measured for the layers deposited by thin processing show a considerably higher (up to 2.5 times) deposition rate for $\mathrm{Xe}^{+}$ions compared to $\mathrm{Ar}^{+}$ ions. This effect is caused by the higher coefficient of sputtering of the above-mentioned target by $\mathrm{Xe}^{+}$ions with the energy of $60 \mathrm{keV}$. An example of such RBS spectra is presented in Fig. 3. It should be mentioned that in all cases the phenomenon of selective sputtering of the cone species has been observed. Therefore, this should be taken into account in practical applications of this processing. The initial target composition is shown in the left-hand corner of Fig. 3. The addition of copper up to 10 at.\% is used to protect grain growth during the layer deposition and form nanostructure coatings [3]. The deposited layers revealed large adhesion to the stainless steel samples. Two effects contribute to this phenomenon. One of them is the ballistic recoil implantation and the second one is the radiation-enhanced diffusion of deposited atoms under the scattered $\mathrm{Xe}^{+}$ion irradiation [10]. Therefore, this processing is favourable and perspective in the cases when the production of composite targets is a problematical one.

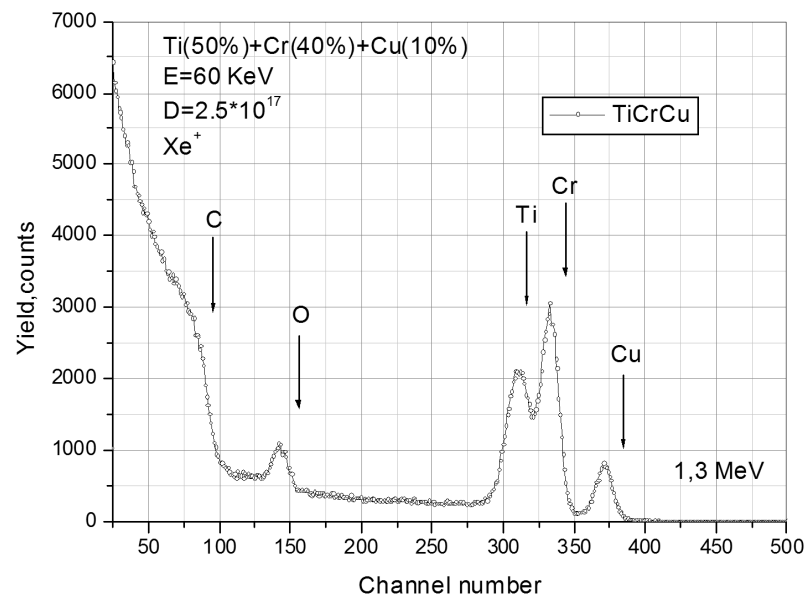

Fig. 3. Typical RBS spectrum of the $\mathrm{Ti}-\mathrm{Cr}-\mathrm{Cu}$ thin film, condensed by ion beam sputtering.

The TEM images and diffraction for the Ti-Si-N and $\mathrm{Ti}-\mathrm{Al}-\mathrm{N}$ coatings deposited by the magnetron method are presented in Fig. 4A and B. According to these examinations, fcc titanium nitride phase with an average grain size of $10 \mathrm{~nm}$ is registered as a main crystalline phase in both systems. It was revealed that $\mathrm{Si}$ and $\mathrm{Al}$ atoms considerably increase intensity of the "diffusion halo" in diffraction patterns. Such a behaviour of diffraction patterns may be attributed to the formation of solid solutions $(\mathrm{TiAl}) \mathrm{N}$ and $(\mathrm{TiSi}) \mathrm{N}$ or TiN nanocrystals covered with thin amorphous layers. In our opinion, the Fourier analysis of intensity distributions in these diffraction patterns can provide additional, useful information to solve this problem.

The above-mentioned optical control of reactive gas flow allowed forming buffer layers with a given gradient

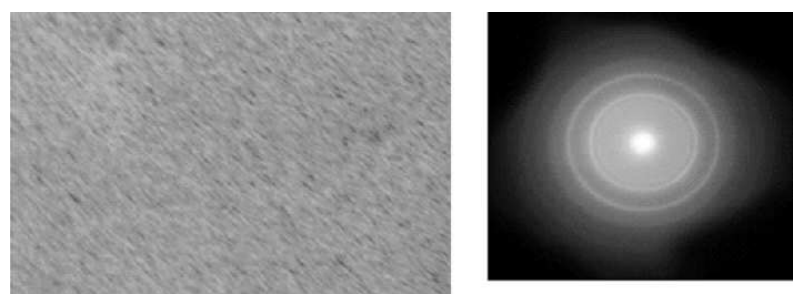

A

200 HM
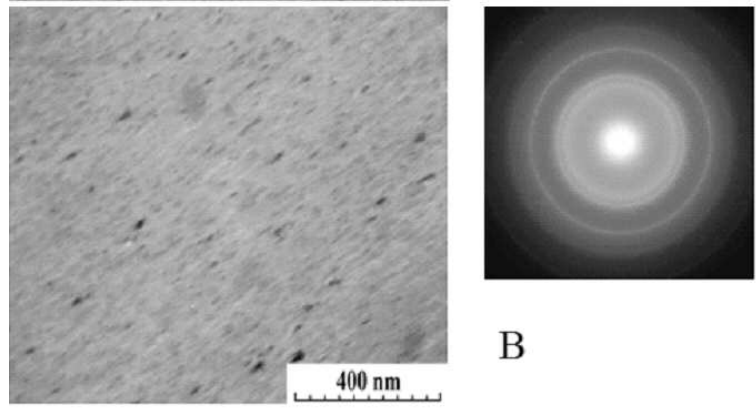

B

Fig. 4. Typical microphotographs and diffraction pattern of the $\mathrm{Ti}-\mathrm{Si}-\mathrm{N}(\mathrm{A})$ and $\mathrm{Ti}-\mathrm{Al}-\mathrm{N}(\mathrm{B})$ thin films, condensed by magnetron sputtering.

of nitrogen concentration. It permits to improve the adhesion in the coating substrate systems. The measured microhardness of the initial substrate and our coatings are displayed in Table.

Microhardness of the examined samples.

TABLE

\begin{tabular}{c|c|c|c|c}
\hline \hline Series & System & $\begin{array}{c}\text { Hardness } \\
{[\mathrm{GPa}]}\end{array}$ & $\begin{array}{c}\text { Value } \\
\text { scattering [\%] }\end{array}$ & $*$ \\
\hline 01 & stainless steel & 2.37 & 6 & 2.37 \\
02 & TiN & 2.63 & 5 & 18.5 \\
04 & TiSiN & 3.85 & 4 & - \\
05 & TiCrN & 3.32 & 4 & - \\
06 & TiAlN & 13.28 & 3 & \\
07 & TiAlN & 31 & 3 & 32 \\
08 & TiAlN(1) & 52.88 & 2 & \\
09 & TiAlN $(2)$ & 28.07 & 2 &
\end{tabular}

An indentation depth in all systems with the coatings was larger than coating thickness. Using low loads, a non-linear load-hardness dependence was observed. The results of the polynomial fit for low loads are shown in the last column of Table (marked by ${ }^{*}$ ). The $\mathrm{Al} / \mathrm{Ti}$ ratio for the series 06 was about 0.43 . A set of samples numbered as 07, 08, 09 in Table and containing various concentrations of the $\mathrm{Al}(\mathrm{Al} / \mathrm{Ti}$ ratio was $0.43,0.55$, and 0.35 , respectively) was examined by the Oliver-Pharr method using the maximum loads in the range of $5-120 \mathrm{mN}$. The maximum load was selected in such a way that the maximum indentation depth did not exceed $40 \%$ of the coating thickness to avoid the influence of the substrate. The test cycle of loading and unloading lasted $50 \mathrm{~s}$. The hardness, 
Young's modulus $E$, and elastic work $W$ were calculated from the load-unload displacement curves. The data in Table illustrates a strong effect of $\mathrm{Al}$ concentration in achieving coatings with high hardness.

Wear tests of the deposited layers show that the magnetron sputtered films provide the best wear protection of the stainless steel surface. The effect of wear decrease in the "dry" steel-coated steel wear experiments amounts to one or two orders of the magnitude. In such coatings high adhesion of the deposited films plays an important role. The standard ways to improve the adhesion are high substrate temperature, previous ion etching and ion beam assistance as well as buffer gradient layer formation. The best wear protection was revealed for the $\mathrm{Ti}-\mathrm{Al}-\mathrm{N}$ systems deposited in a narrow range of the component concentrations and substrate temperatures.

Friction coefficient measurements were performed in "dry" conditions in geometry disk-on-plate. Figure 5 illustrates a few examples of the obtained data.

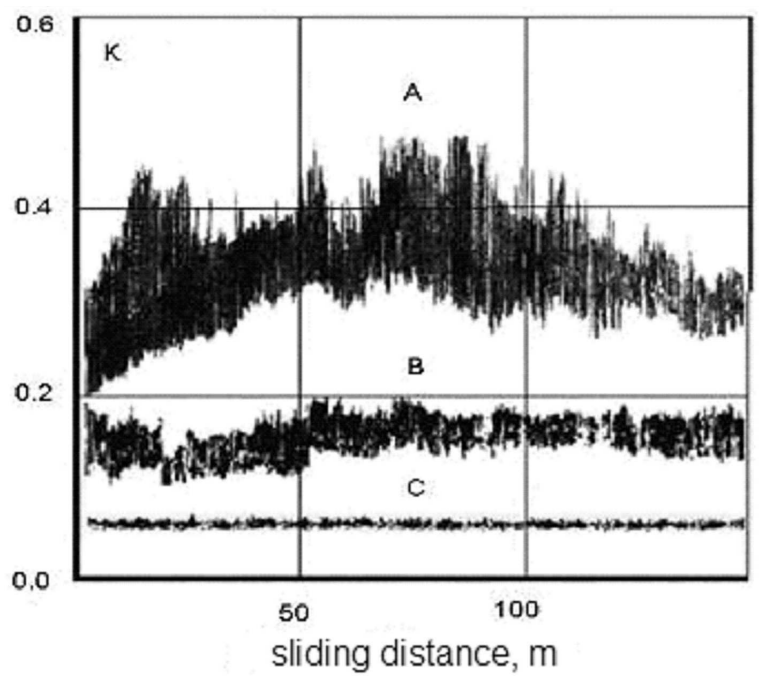

Fig. 5. Friction coefficient versus sliding distance for the $\mathrm{Ti}-\mathrm{Si}-\mathrm{N}$ coating without gradient sheets $(\mathrm{A})$, clean steel surface (B), and the Ti-Al-N coated steel (C).

As it is observed, the layers with poor adhesion reveal the dominant abrasive wear mechanism (A). The minimal friction coefficient, caused by minimum surface roughness, good adhesion, and chemical passivity of formed compounds was obtained for deposited $\mathrm{Ti}-\mathrm{Al}-\mathrm{N}$ layers with the gradient layer $(\mathrm{C})$.

\section{Conclusions}

The best compositional uniformity of layers and formation of gradient layers are achieved by the usage of the optically controlled magnetron sputtering, beam assisted deposition is favourable and perspective in the cases when the production of composite targets is a problematical one.

The "beginning-stage" of oxygen contamination must be eliminated for all magnetron sputtered targets with the substrate shielding at an initial stage of processing.

The experimental data illustrates a strong effect of $\mathrm{Al}$ concentration in achieving coatings with high hardness. The best hardness and wear protection are revealed for the $\mathrm{Ti}-\mathrm{Al}-\mathrm{N}$ systems deposited in a narrow range of the component concentrations and substrate temperatures.

\section{Acknowledgments}

Financial support from the Belarussian and Ukrainian Funds of Fundamental Investigations (Joint project No. T11K-058) is acknowledged.

\section{References}

[1] J. Musil, J. Vlcek, Surf. Coat. Technol. 142, 557 (2001).

[2] S. Veprek, S. Reiprich, Thin Solid Films 268, 64 (1995).

[3] A. Cavaleiro, G.T. de Hosson, Nanostructure Coatings, Springer Sci. + Business Mediac, LLC, 2006, p. 750 .

[4] J.E. Sundgren, Thin Solid Films 128, 21 (1985).

[5] E. Vera, G.K. Wolf, Nucl. Instrum. Methods Phys. Res. B 148, 917 (1999).

[6] C. Jarms, H.R. Stock, P. Mayr, Surf. Coat. Technol. 108-109, 206 (1998).

[7] S. Veprek, G.J. Maritza, V. Heijman, Surf. Coat. Technol. 202, 5063 (2008).

[8] S. Veprek, G.J. Maritza, V. Heijman, P. Karvankova, J. Prochazka, Thin Solid Films 476, 1 (2005).

[9] Z.W. Xie, L.P. Wang, X.F. Wang, L. Huang, Y. Lu, J.C. Yan, Nucl. Instrum. Methods Phys. Res. B 271, 1 (2012).

[10] P. Żukowski, F.F. Komarov, Cz. Karwat, K. Kiszczak, Cz. Kazak, A.S. Kamyshan, Vacuum 83, 204 (2009).

[11] V.C. Oliver, G.M. Pharr, J. Mater. Res. 7, 1564 (1992). 